\title{
Robust abundance estimate for endangered river dolphin subspecies in South Asia
}

\author{
Gillian T. Braulik ${ }^{1,2, *}$, Zahid I. Bhatti ${ }^{3}$, Tahir Ehsan ${ }^{2}$, Babar Hussain ${ }^{4}$, \\ Abdul R. Khan ${ }^{5}$, Ashfaq Khan ${ }^{6}$, Uzma Khan ${ }^{7}$, Khalil U. Kundi ${ }^{8}$, Rafiq Rajput ${ }^{9,7}$, Albert \\ P. Reichert ${ }^{2,10}$, Simon P. Northridge ${ }^{1}$, Hussain B. Bhagat ${ }^{9}$, Richard Garstang ${ }^{2}$ \\ ${ }^{1}$ Sea Mammal Research Unit, Scottish Oceans Institute, University of St. Andrews, St. Andrews, Fife KY16 8LB, UK \\ ${ }^{2}$ Pakistan Wetlands Programme, Islamabad, Pakistan \\ ${ }^{3}$ Lahore Zoological Gardens, Shahrah-e-Quaid-e-Azam, Lahore, Pakistan \\ ${ }^{4}$ World Wide Fund for Nature (WWF)-Pakistan, Fortune Center, Pakistan Employees Cooperative Housing Society (PECHS), \\ Shahrae Faisal, Karachi, Pakistan \\ ${ }^{5}$ Halcrow Pakistan, PECHS, Karachi, Pakistan \\ ${ }^{6}$ Adventure Tourism Section, Tourism Development Pakistan, Lahore, Pakistan \\ ${ }^{7}$ WWF-Pakistan, Lahore, Pakistan \\ ${ }^{8}$ Khyber Pakhtunkhwa (KPK) Wildlife Department, Peshawar, Pakistan \\ ${ }^{9}$ Sindh Wildlife Department, Karachi, Pakistan \\ ${ }^{10}$ Downstream Research Group, Macon, Georgia 31201, USA
}

\begin{abstract}
Robust estimates of absolute abundance are vital for management of threatened species, but these have rarely been generated for endangered South Asian river dolphins due to methodological challenges. An estimate of abundance for the Indus River dolphin in 2006 was generated by conducting tandem vessel-based direct counts; conditional likelihood capture-recapture models were then used to correct for missed animals. Group size and sighting conditions were included as covariates, and abundances of the 3 largest subpopulations were estimated as 101 (coefficient of variation, $\mathrm{CV}=44.1 \%)$ between Chashma and Taunsa barrages, $52(\mathrm{CV}=14.9 \%)$ between Taunsa barrage and Ghazi Ghat, and 1289 (CV $=33.4 \%)$ between Guddu and Sukkur barrages. A total of $75.3 \%$ of groups were seen by both independent survey teams, and single animals were almost 5 times more likely to be missed than groups of 3 or more. Providing groups can be matched with minimal error, this survey method shows good potential for abundance estimation of dolphins in confined habitat and the shallow rivers of South Asia. Dolphin encounter rates within the Guddu-Sukkur subpopulation $\left(10.35 \mathrm{~km}^{-1}\right)$ are the highest reported for any river dolphin. Direct counts conducted over a $35 \mathrm{yr}$ period, suggest that this subpopulation may have been increasing in abundance, probably due to the cessation of hunting and possible immigration from other subpopulations. The future of South Asian river dolphins is intimately tied to water security in the region, and escalating and competing demands for freshwater mean that the long-term future of South Asia's river dolphins is uncertain.
\end{abstract}

KEY WORDS: River dolphins · Platanista $\cdot$ Abundance · Trends · South Asia · Capture-recapture · Pakistan

Resale or republication not permitted without written consent of the publishe

\section{INTRODUCTION}

The world's freshwaters are biodiversity hotspots, inhabited by almost $6 \%$ of described species yet covering only $0.8 \%$ of the earth's surface. However, they are also hotspots of endangerment and are experiencing declines in biodiversity far greater than those in terrestrial ecosystems (Dudgeon et al. 2006, Strayer \& Dudgeon 2010). Freshwater dolphins and porpoises are among the world's most threatened 
mammals. Nine river systems or brackish lagoons in Asia have resident cetacean populations, and all are listed on the IUCN Red List as Endangered or Critically Endangered (with the exception of two that are yet to be evaluated) (IUCN 2010). After decades of concern about its status, the baiji, or Yangtze River dolphin Lipotes vexillifer, the sole representative of an entire mammalian family, is believed to be extinct (Turvey et al. 2007). Asian river dolphins share their lowland river habitat with hundreds of millions of people, resulting in high mortality rates from hunting or entanglement in fishing gear, populations fragmented by dams and barrages, and habitat severely depleted by water extraction and degraded by pollution and altered flow regimes. The baiji's extinction clearly demonstrates that without appropriate and timely action, the future of the remaining freshwater cetaceans is precarious.

\section{Status of the Indus dolphin}

The South Asian river dolphin Platanista gangetica occurs in a monotypic genus that includes the Indus River dolphin Platanista gangetica minor, resident in the Indus River system in Pakistan and India, and the Ganges River dolphin Platanista gangetica gangetica found in the Ganges-Brahmaputra and Karnaphuli-Sangu River systems in India, Bangladesh, and Nepal. The species and both subspecies are listed as Endangered in the IUCN Red List (Braulik et al. 2004, Smith et al. 2004).

The Indus River rises in Tibet, flows through the Himalayas and Karakoram mountains and then flows south for approximately $2000 \mathrm{~km}$ across arid, intensively cultivated and densely populated plains of Pakistan. The lower Indus River system has been transformed into an intensively managed irrigation scheme, including several high dams, multiple inter-river link canals, and numerous barrages (gated-diversion dams) that divert the majority of the river's flow into canals to irrigate agricultural land. The Indus dolphin persists within this system, but its range has declined by $80 \%$, its population is fragmented by barrages, and its habitat is degraded due to water diversion. In 2001, dolphins were recorded within around $1000 \mathrm{~km}$ of the Indus mainstem in 5 subpopulations separated by barrages, and the metapopulation was estimated as approximately 1200 (Braulik 2006). A sixth very small dolphin subpopulation, located more than $600 \mathrm{~km}$ from all the others, was recently discovered in the Beas River, India (Behera et al. 2008).

\section{Methodological challenges to surveying Platanista spp.}

The ability to estimate abundance with relative accuracy and precision is imperative for assessing the status of endangered species and monitoring the effectiveness of conservation measures. The Subcommittee on Small Cetaceans of the International Whaling Commission (IWC) noted in 2000 that few reliable abundance estimates were available for any species of freshwater cetacean and that the habitat and behaviour of these animals posed particular problems for abundance estimation (IWC 2001). Identifying an appropriate survey methodology for South Asian river dolphins is especially challenging as the 2 principal methods used to estimate abundance, i.e. distance sampling and photo-identification, are difficult or impossible to apply (Smith \& Reeves 2000, Dawson et al. 2008). In the absence of a more robust method, direct counts in discrete river sections have generally been conducted. The counts have not included measures of precision and are underestimates of the real population size, as no correction was made for animals that were missed when they were underwater (availability bias) or that surfaced in view but were not recognised (perception bias) (Marsh \& Sinclair 1989, Smith et al. 2006). The IWC sub-committee strongly recommended that appropriate methods be developed so that surveys of river cetaceans result in statistically robust estimates of abundance (IWC 2001).

Capture-recapture analysis of photo-identified animals is commonly used to estimate abundance of cetaceans (Hammond 2009). This method relies on capturing images of uniquely marked animals; the proportion of identified individuals recaptured during subsequent sampling events is then used to estimate population abundance (Borchers et al. 2002). This method has very limited possibilities for Platanista spp. because (1) they are extremely difficult to photograph as they surface alone, unpredictably, for about one second and they do not approach boats, and (2) they lack a prominent dorsal fin and rarely possess any readily identifying features. Not a single individual could be identified from 1200 photographs of Ganges River dolphins (Smith \& Reeves 2000).

The primary challenge to the application of line or strip transect methods in the Indus, Ganges and Brahmaputra Rivers is that rivers are very shallow and survey vessels are restricted to travelling down the thalweg (the line that follows the deepest part of the river) along a single curving transect that periodically approaches alternate banks as the river mean- 
ders. Indus dolphin distribution is biased towards the deeper water found along the survey transect (G. Braulik unpubl. data). To avoid the unrealistic assumption that animals in the population are randomly distributed when using distance sampling, the random or systematic placement of an adequate number of transects is required. This allows for reliable extrapolation (1) from observations made in the sampled area to the entire region of interest, and (2) of the observed perpendicular sighting distances to estimate the proportion of animals counted. A thalweg transect survey unavoidably samples unrepresentative habitat as it passes through areas with higher densities, and in addition the animals are unlikely to be uniformly distributed in the surveyed strips. Other less significant challenges to distance sampling in this environment include measuring perpendicular sighting distances when surveying moving objects from a sharply curving path (Hiby \& Krishna 2001), frequent constrictions in the river channel that cut off the potential detection width causing a narrowing or unusual shoulder in the detection function (Dawson et al. 2008), and the presence of a downstream population density gradient (Braulik 2006) that complicates extrapolation of data from one area to another.

Transects running from bank to bank, perpendicular to the flow, are used for line transect surveys of cetaceans in the Amazon River (Vidal et al. 1997, Martin \& da Silva 2004), but in the comparatively shallow, sand-bedded, South Asian rivers navigational constraints preclude this approach. A single transect parallel to, and a standard distance from, the river banks has also been used for strip transect surveys in the Amazon (Vidal et al. 1997, Martin \& da Silva 2004) and for adapted line transect surveys on the Yangtze River (Zhao et al. 2008), but this is not possible on South Asian rivers as channel width changes rapidly and vessels cannot maintain a standard distance from the banks due to shallows. Aerial surveys have not been attempted for South Asian river dolphins, but high water turbidity would prevent animals being detected below the surface, and the extremely brief surfacing time would make detection from above unlikely.

Aerial surveys of terrestrial and marine mammals frequently obtain simultaneous counts using independent observer teams, so that mark-recapture can be used to correct abundance estimates for missed animals (Samuel \& Pollock 1981, Graham \& Bell 1989, Marsh \& Sinclair 1989, Crete et al. 1991, Carretta et al. 1998, Hiby \& Lovell 1998). A similar method using independent teams on a single vessel was used by Smith et al. (2006) to estimate abun- dance of Ganges River dolphins and Irrawaddy dolphins Orcaella brevirostris in the Bangladesh Sundarbans. We have adapted these methods, and present here an appropriate and robust method for estimating abundance of dolphins in confined habitats such as rivers in South Asia. Abundance of Indus River dolphins was estimated by conducting direct counts using independent observation teams on vessels travelling in tandem along a thalweg transect, and conditional-likelihood capture-recapture models were used to correct for missed animals.

\section{MATERIALS AND METHODS}

\section{Field surveys}

The survey was conducted from 23 March to 24 April 2006 when Indus discharge was at its annual low. The expedition covered habitat in each of the 5 extant Indus dolphin subpopulations, including river channels between Jinnah barrage and Ghazi Ghat bridge (65 km downstream of Taunsa barrage), Guddu and Sukkur barrages and Sehwan Sharif and Kotri barrage (Fig. 1). Field methods were the same as those employed during a direct count survey in 2001 (see Braulik 2006). Two oar-powered boats travelled downstream, in tandem and separated by 1 to $3 \mathrm{~km}$ (5 to $35 \mathrm{~min}$ ). Significant secondary channels were identified using satellite images and were surveyed by the rear boat, while the forward vessel continued along the main channel in non-tandem survey effort. All observers received training prior to the survey and each vessel had a minimum of 2 observers with prior dolphin survey experience. Survey effort was recorded and the effect of wind on the river surface evaluated according to the following 'river state' scale: $0=$ water surface glassy; 1 = ripples without crests; 2 = small wavelets with crests but no whitecaps; 3 = large wavelets with scattered white-caps; $4=$ small waves with fairly frequent white-caps. When dolphins were sighted, their distance was estimated, and nearby objects, such as the river banks, were measured with laser range-finders to improve the accuracy of distance estimates. Generally, dolphins were sighted downstream of the survey vessels and remained relatively stationary, so that the vessels approached and passed through groups while proceeding downstream. We recorded a 'detection location' with a GPS when a dolphin was first sighted and an 'exact location' when the centre of the group was perpendicular to the vessel. Animals judged to be less than $1 \mathrm{~m}$ in length were designated as calves. 


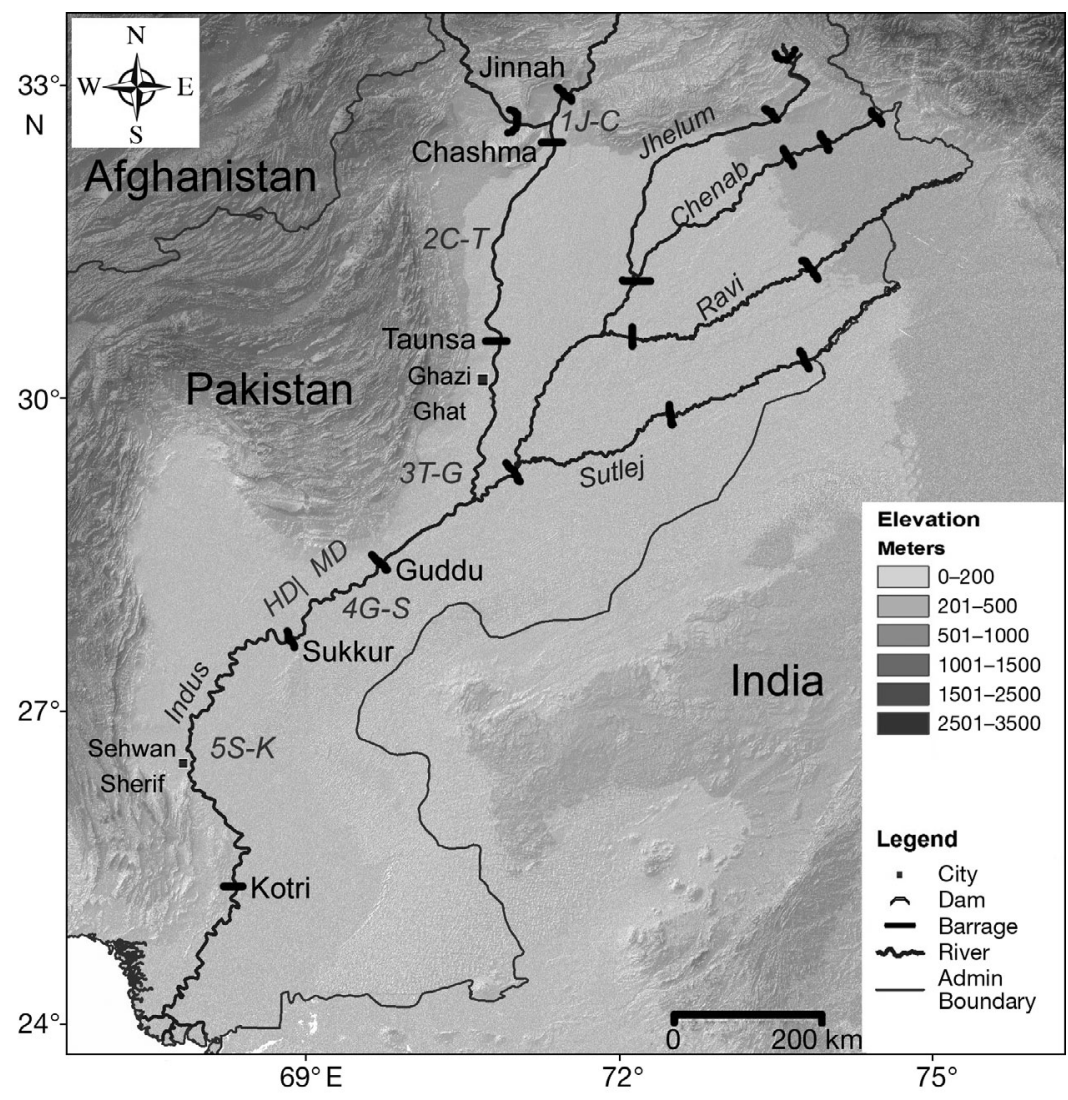

Fig. 1. Map of the Indus River system illustrating the barrages that form the boundaries between the 5 dolphin subpopulations. Each subpopulation is denoted by the following acronyms that include the sequential number of the subpopulation and the barrages it is bounded by: 1J-C (Jinnah to Chashma), 2C-T (Chashma to Taunsa), 3T-G (Taunsa to Guddu), 4G-S (Guddu to Sukkur), 5S-K (Sukkur to Kotri). MD: moderate density subsection of the Guddu to Sukkur subpopulation; HD: high density subsection of the Guddu to Sukkur subpopulation

Indus dolphins typically occur as loose aggregations of individuals, so following previous authors, a group was defined as animals occurring within $500 \mathrm{~m}$ in similar fluvial habitat such as meander bends or channel constrictions (Smith et al. 2006). In the lower half of the Guddu-Sukkur river section, encounter rates were very high; dolphins occurred continuously with no obvious gaps between groups, and we used river features, such as constrictions, or mid-channel bars, to delineate groups and facilitate counting.

\section{Identification of matched sightings}

All sighted dolphin groups were considered to be 'captured' and were then classified as duplicates or 'matches' if they were seen by both survey vessels, or unique if they were 'missed' by 1 boat. Sightings were classified as matches based on the distance between their 'exact' geographic positions combined with any group movement direction noted in the field. Using ArcView 3.2, the distance between dolphin groups was measured along the centre of the river channel, and a frequency distribution of the distance between the exact geographic positions of potentially matched dolphin groups generated. The obvious clumping of distances was used to guide selection of an appropriate distance threshold with which to classify groups as matched. Use of a small threshold distance would result in recognition of more missed sightings and a larger abundance estimate; conversely a wide threshold distance would generate fewer missed sightings and a smaller estimate of abundance. Field observations indicate that Indus dolphins often remain in circumscribed habitat for periods of up to an hour (G. Braulik pers. obs.) and that a relatively small threshold distance could be applied. We selected a threshold distance that allowed for some dolphin movement between detections but did not specifically model movement because no quantitative data have been published on the movements or swimming speeds of Indus or Ganges dolphins that could reliably contribute to a model. We assumed that matches were made without error; however, to test how robust our results were to the selection of threshold distance, we conducted a sensitivity analysis to compare the influence of 6 candidate thresholds ( 300 to $800 \mathrm{~m}$ ) on the number of sightings identified as matched.

\section{Abundance estimation}

Estimating number of groups

Abundance was estimated separately for each subpopulation. Sightings made during tandem survey effort were analysed using mark-recapture for closed populations in a Huggins conditional-likelihood model implemented by the program MARK. Capture probabilities are modelled as a function of sighting covariates according to the following formula (Huggins 1989): 


$$
\operatorname{logit}\left(p_{i k}\right)=\ln \left(\frac{p_{i k}}{1-p_{i k}}\right)=\beta_{0}+\sum_{j} \beta_{j} x_{j k}
$$

where logit $=$ link function, $p=$ the probability of capture, $i=$ forward or rear survey boat, $k=$ dolphin group, $j=$ covariate, $\beta_{0}=$ intercept and $\beta_{j}=$ slope for covariate value $x_{j}$.

Group abundance and variance during tandem effort was estimated within MARK using a HorvitzThompson like estimator (Horvitz \& Thompson 1952):

$$
\hat{g}_{\mathrm{t}}=\sum_{\mathrm{k}=1}^{g_{\mathrm{t}}} \frac{1}{\hat{p}_{k}} \quad \operatorname{var}\left(\hat{g}_{\mathrm{t}}\right)=\sum_{\mathrm{k}=1}^{g_{\mathrm{t}}} \frac{1}{\hat{p}_{k}}\left(1-\hat{p}_{i}\right)
$$

where $\hat{g}_{\mathrm{t}}$ is the estimated number of groups present during tandem effort and $\hat{p}_{k}$ is the estimated probability that group $k$ was detected by either platform.

Covariates included in the model were selected based on similar studies, combined with knowledge of the Indus River environment and of Indus dolphin behaviour. Perception bias of Ganges dolphins was influenced only by group size, not by sighting conditions or channel width (Smith et al. 2006). Detection of harbour porpoise Phocoena phocoena was influenced by group size and sea state (Hammond et al. 2002), and the vaquita $P$. sinus by sea state (Gerrodette et al. 2011). We included group size, river surface state and sighting vessel as covariates in models for each subpopulation. Group sizes used were those recorded in the field. Although possible error in group size estimation is not explicitly accounted for, the effect on the abundance estimate and variance is expected to be small. When group size estimates for matched groups differed, the estimate from the forward vessel was always used, as this was considered more reliable. Models were selected using Akaike's information criterion for small sample sizes (AICc), according to recommended guidelines (Burnham \& Anderson 2002). To account for uncertainty in model selection, if the best fitting models were separated by less than 2 AICc points they were averaged on the basis of their normalized AICc weights (Stanley \& Burnham 1998).

\section{Estimating mean group size}

Mean group size was estimated ignoring errors in recorded size but attempting to correct for smaller groups being less detectable. To produce an estimate of mean group size $(\bar{s})$ in each subpopulation, the detected number of groups of each group size $\left(n_{j}\right)$ were corrected by the average detection probability of a group of particular size $\left(\hat{p}_{j}\right)$ output by MARK, and this was used to estimate a group size distribution, from which the mean was determined:

$$
\bar{s}=\frac{\sum_{j=1}^{s_{\max }} \frac{n_{j} \cdot j}{\hat{p}_{j}}}{\sum_{j=1}^{s_{\max }} \frac{n_{j}}{\hat{p}_{j}}}
$$

The variance in estimated mean group size was generated from the sample variance of the estimated recorded group sizes, after adjusting for variability in detection probability.

\section{Non-tandem effort}

The capture-recapture method described above was reliant on tandem survey effort; however, portions of non-tandem survey effort were conducted in all river sections. In addition, the 4G-S subpopulation (Fig. 1) was subdivided into 2 strata: the upper $106 \mathrm{~km}$ with moderate dolphin density (MD) (3.63 dolphins linear $\mathrm{km}^{-1}$ ), and a lower $98 \mathrm{~km}$ with high density (HD) (9.06 dolphins linear $\mathrm{km}^{-1}$ ). In the HD subsection there were no obvious gaps between aggregations, which made it impossible to determine whether sightings from the 2 vessels matched. Capture-recapture using tandem survey data was therefore not conducted on the HD subsection, and these data were treated as non-tandem. To account for groups missed in each subpopulation during non-tandem survey periods we applied a correction factor $\left(f_{\mathrm{m}}\right)$ determined from the tandemeffort survey: $f_{\mathrm{m}}=\hat{g}_{\mathrm{t}} / g_{\mathrm{ft}}$ where $g_{\mathrm{ft}}$ is the number of groups seen by the forward vessel during tandem effort. The group size from tandem effort was applied to sightings made during nearby non-tandem effort. However, in the 4 G-S HD subsection, which was surveyed entirely in non-tandem effort, group size was substantially larger than in all other areas, and corrected group size was therefore calculated using the method described above, applying the group size detection probabilities determined from tandem survey effort in the 4 G-S MD subsection. Sighting conditions in side channels were very different from the main channel, and it was considered inappropriate to apply the main channel group correction factor to these areas, so individuals seen in side channels $\left(n_{\mathrm{s}}\right)$ were added to main channel sightings without correction.

\section{Estimating abundance}

A binomial generalised linear model (GLM) was used to test the relationship between the time lag between tandem vessels and the probability that a dolphin group was missed. Based on this, where the time lag between survey vessels was long, tandem survey data 
were reclassified as non-tandem, so that the probability that a sighting was missed was independent of time lag. Abundance of dolphins in each subpopulation seen during tandem survey effort $\hat{N}_{\mathrm{t}}$ was estimated as $\hat{g}_{\mathrm{t}}{\overline{S_{\mathrm{t}}}}_{\mathrm{t}}$ and the coefficient of variation, $\mathrm{CV}$ :

$$
\operatorname{CV}\left(\hat{N}_{\mathrm{t}}\right) \approx \sqrt{\left[\mathrm{CV}^{2}\left(\hat{g}_{\mathrm{t}}\right)+\mathrm{CV}^{2}\left(\bar{S}_{\mathrm{t}}\right)\right]}
$$

Abundance of dolphins in each subpopulation seen during non-tandem survey effort $\hat{N}_{\text {nt }}$ was estimated as $\hat{g}_{\mathrm{nt}} \bar{S}_{\mathrm{nt}}+n_{\mathrm{s}}$ and the CV:

$$
\operatorname{CV}\left(\hat{N}_{\mathrm{nt}}\right) \approx \sqrt{\left[\mathrm{CV}^{2}\left(\hat{f}_{\mathrm{m}}\right)+\mathrm{CV}^{2}\left(\bar{S}_{\mathrm{nt}}\right)\right]}
$$

The CV of the correction factor is derived from:

$$
\operatorname{SE}\left(\hat{f}_{\mathrm{m}}\right)=\frac{\sqrt{\operatorname{var}\left(\hat{g}_{\mathrm{t}}\right)}}{g_{\mathrm{ft}}}
$$

Total subpopulation abundance was generated by summing the tandem and non-tandem sightings, and total metapopulation abundance by totalling the abundance in each subpopulation. CVs were combined using the delta method, and if there were shared factors between strata these were factored out to account for covariance (Buckland et al. 2001, Gerrodette et al. 2011).

Log-normal confidence intervals (CI), where the lower limit cannot be smaller than the number of unique individuals sighted $\left(M_{\mathrm{t}+1}\right)$, were calculated according to the following (Williams et al. 2002):

Lower CI $=M_{\mathrm{t}+1}+\left(\frac{\hat{f}_{0}}{C}\right)$ Upper CI $=M_{\mathrm{t}+1}+\left(\hat{f}_{0} C\right)$

where:

$$
\begin{aligned}
& \hat{f}_{0}=\hat{N}-M_{\mathrm{t}+1}, \quad \text { and } \\
& C=\exp \left\{1.96\left[\ln \left(1+\frac{\operatorname{var}(\hat{N})}{\hat{f}_{0}^{2}}\right)\right]^{1 / 2}\right\}
\end{aligned}
$$

The confidence intervals generated for the current study are particularly skewed because the lower bounds are constrained to lie between the abundance estimates and $M_{\mathrm{t}+1}$, and as sighting probabilities were high these values are similar. By contrast, the upper bound of the confidence interval is unconstrained and is influenced by the precision of the abundance estimates.

\section{Availability bias}

The contribution of dolphin availability to total detection bias (corrected for by the tandem surveys) was investigated using radial dolphin sighting distances, vessel speed, and the dive and surface behaviour of groups of different sizes. In the dry season of 2008, between Chashma and Taunsa barrages, dive times of groups or individuals were recorded with a stop watch from a vantage point on the river bank. A dive time was the interval between surfacings that lasted longer than 2 s. Group size was recorded when dive time monitoring began, and if this subsequently changed, the time and new group size were recorded. Water depth at group locations was not specifically measured but included a range of those used by the subspecies. Surfacing of this species is so rapid and unpredictable that it is not possible to accurately measure surface interval in the field; therefore, surfacings were recorded with digital video and surface time measured by sequentially viewing each frame. Footage was recorded at 25 frames $\mathrm{s}^{-1}$, resulting in surface intervals accurate to $0.08 \mathrm{~s}$. The probability that a group was available to be seen by observers was determined according to the following (Barlow et al. 1988): $a=s t+w / s t+d$, where $a=$ the number of surfacings when a survey vessel was present, $s t=$ mean surface time, $d=$ mean dive time, and $w=$ the time window that individuals or groups were within range of observers, determined using sighting distances and vessel speed.

\section{RESULTS}

The survey covered $808 \mathrm{~km}$ of the Indus River main channel and $126 \mathrm{~km}$ of adjacent secondary channels. Environmental conditions were excellent: $92 \%$ of survey effort was conducted in a river surface state of 2 or less, and $46 \%$ was in glassy conditions. There was no significant difference between the daily counts recorded by each boat (paired $t$-test, $\mathrm{p}=0.704$ ). Mean dolphin radial sighting distance was $401 \mathrm{~m}$ (SD = $279.1 \mathrm{~m}$ ), consistently greater than half the mean river width (200 to $300 \mathrm{~m}$ ), and sightings often occurred at distances up to $1 \mathrm{~km}$ (Fig. 2). Although these are radial distances, not perpendicular distances, this still illustrates that the majority of surfacings within the river channel could be detected. Dolphin encounter rate and mean group size increased from the northern extreme of the range downstream to Sukkur barrage. As mean group size increased, the distance between groups decreased. Direct counts derived from the sum of group size estimates of the forward survey vessel plus animals sighted in secondary channels totalled: 1 in section $1 \mathrm{~J}-\mathrm{C}$ (Jinnah to Chashma barrages); 82 in section 2C-T (Chashma to Taunsa barrages); 44 between Taunsa barrage and Ghazi Ghat bridge (3TGG); 1275 in section 4G-S (Guddu to Sukkur barrages); and 4 in section $5 \mathrm{~S}-\mathrm{K}$ (Sukkur to Kotri barrages). Calves accounted for approximately $14 \%$ 


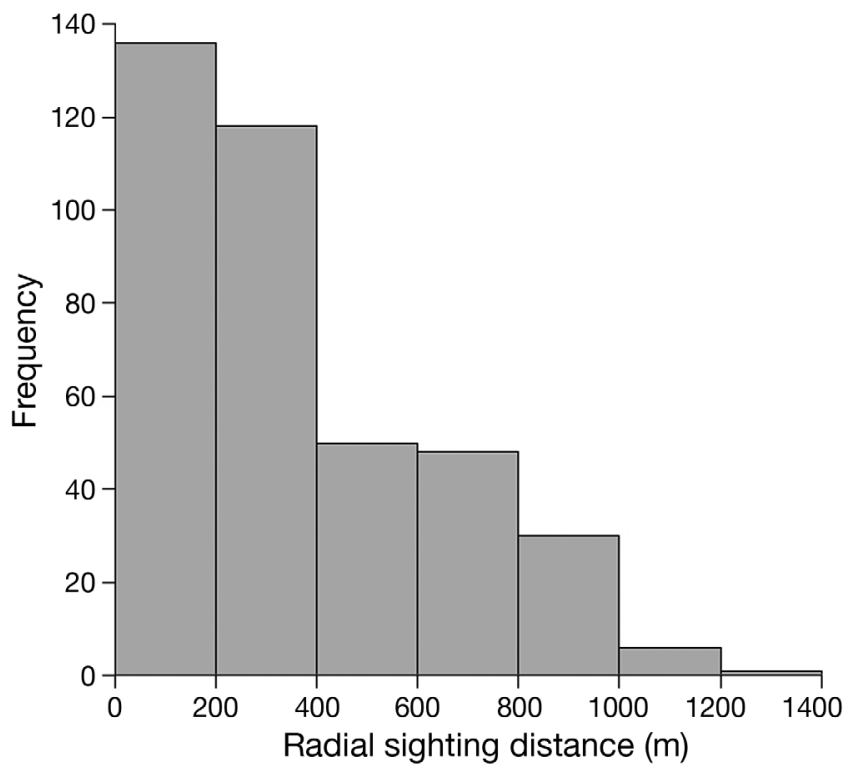

Fig. 2. Frequency of radial sighting distances of the Indus River dolphin Platanista gangetica minor. The available survey strip, represented by half mean river width, varies between 200 and $300 \mathrm{~m}$ depending on the section of river

of total individuals in 2C-T, $7 \%$ in $3 \mathrm{~T}-\mathrm{GG}$, and $11 \%$ in the $4 \mathrm{G}-\mathrm{S}$ section. Dolphins were sighted in secondary channels only in the $2 \mathrm{C}-\mathrm{T}$ ( 4 ind.) and $4 \mathrm{G}-\mathrm{S}$ (5 ind.) sections, and encounter rates in these channels were very low, $0.08 \mathrm{~km}^{-1}$ and $0.3 \mathrm{~km}^{-1}$, respectively, compared to adjacent uncorrected main channel encounter rates of $0.27 \mathrm{~km}^{-1}$ and $6.23 \mathrm{~km}^{-1}$, respectively.

\section{Identification of matched sightings}

Matching of sightings in most areas was unambiguous because there were long distances between detections, encounter rate was low $(<1$ dolphin $\mathrm{km}^{-1}$ ), groups can only move in 2 directions, up- or downstream, and most potentially matched groups were very close to one another. Of potentially matched sightings (those within $2 \mathrm{~km}$ ) the geographic locations of $88 \%$ occurred within $600 \mathrm{~m}$, and $78 \%$ were within 400 m (Fig. 3). Six hundred metres was selected as the appropriate threshold distance for determining matched sightings because it encompassed the majority of probable matches, allowed for some group movement between surveys, and was greater than the $500 \mathrm{~m}$ distance used to define a group. In the matching sensitivity analysis, contrasting the $300,400,500,700$ and $800 \mathrm{~m}$ distance thresholds to the $600 \mathrm{~m}$ threshold resulted in different missed/matched classifications for a maximum of 5

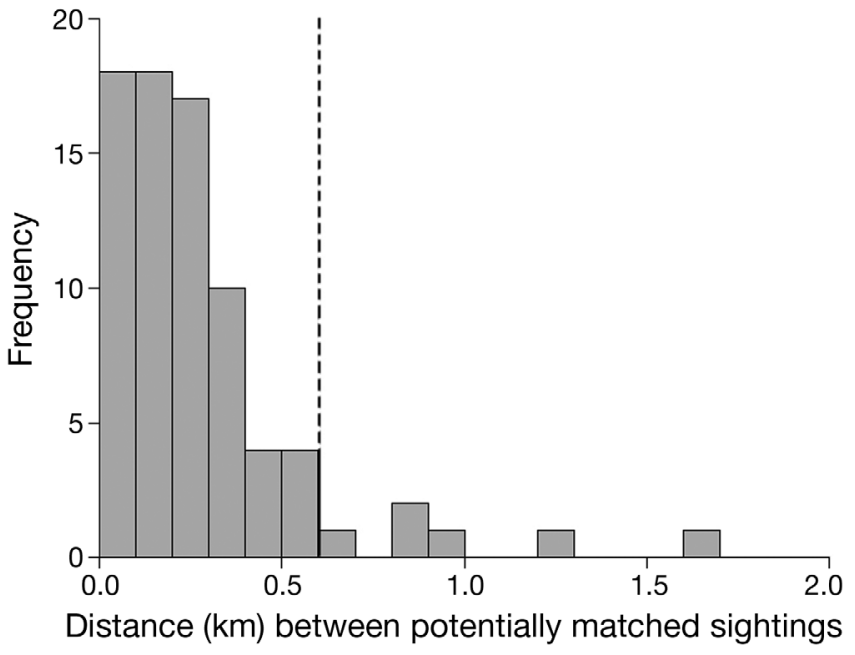

Fig. 3. Distance between the exact geographic positions of potentially matched groups of Platanista gangetica minor. Vertical line indicates the $600 \mathrm{~m}$ distance threshold selected to classify sightings as matched in the tandem surveys

groups (26 versus 31 matches) and less than $5 \%$ difference in the corrected number of groups estimated by the Huggins mark-recapture model (Table 1). The largest differences corresponded to the narrowest $300 \mathrm{~m}$ threshold. The sensitivity analysis clearly demonstrates that changing the threshold distance used to define matched groups does not exert a great influence on the resulting estimates of abundance.

\section{Estimation of abundance}

Based on the GLM, 4 sightings that occurred when there was more than 35 min separating the vessels

Table 1. Comparison of different distance thresholds used to identify matched and missed Indus River dolphin Platanista gangetica minor sightings with the $600 \mathrm{~m}$ distance (in bold) finally selected. Number of groups seen by the forward vessel $\left(n_{\mathrm{f}}\right)$, rear vessel $\left(n_{\mathrm{r}}\right)$ and by both vessels $\left(n_{\mathrm{fr}}\right)$ during tandem survey effort between Chashma and Ghazi Ghat; $\hat{g}_{t}$ : correct number of groups calculated using the Huggins model ${ }_{i} \mathrm{SE}\left(\hat{g}_{\mathrm{t}}\right)$ : standard error of the correct number of groups

\begin{tabular}{|lccccc|}
\hline $\begin{array}{l}\text { Distance } \\
\text { threshold }(\mathrm{m})\end{array}$ & $n_{\mathrm{f}}$ & $n_{\mathrm{r}}$ & $n_{\mathrm{fr}}$ & $\hat{g}_{\mathrm{t}}$ & $\mathrm{SE}\left(\hat{g}_{\mathrm{t}}\right)$ \\
\hline 300 & 41 & 41 & 26 & 56.8 & 3.6 \\
400 & 41 & 41 & 29 & 55.1 & 2.8 \\
500 & 41 & 41 & 31 & 54.2 & 2.4 \\
$\mathbf{6 0 0}$ & $\mathbf{4 1}$ & $\mathbf{4 1}$ & $\mathbf{3 1}$ & $\mathbf{5 4 . 2}$ & $\mathbf{2 . 4}$ \\
700 & 41 & 41 & 32 & 53.8 & 2.2 \\
800 & 41 & 41 & 32 & 53.8 & 2.2 \\
\hline
\end{tabular}


were reclassified as occurring during non-tandem effort, and in the remaining dataset the probability that a dolphin group was missed was independent of survey time lag (GLM, $\mathrm{p}=0.12)$. In $50 \%$ of tandem survey effort, the vessels were separated by less than $10 \mathrm{~min}$, and in $75 \%$, the boats were less than $20 \mathrm{~min}$ apart. Sighting probability was high; $75.3 \%$ of groups were seen by both independent survey teams, and single animals were almost 5 times more likely to be missed than groups of 3 or more. Markrecapture analysis was conducted on the tandem survey data from each of the 3 largest dolphin subpopulations but was not conducted on the sightings that occurred between Jinnah and Chashma barrages (1 animal) and Sukkur and Kotri barrages (4 animals) due to the small sample size.

\section{Chashma to Taunsa}

In the $2 \mathrm{C}-\mathrm{T}$ section, during tandem survey effort the forward boat recorded 27 groups, the rear boat recorded 26 groups, and 18 sightings were matches, with 17 unique. Nine groups were sighted during

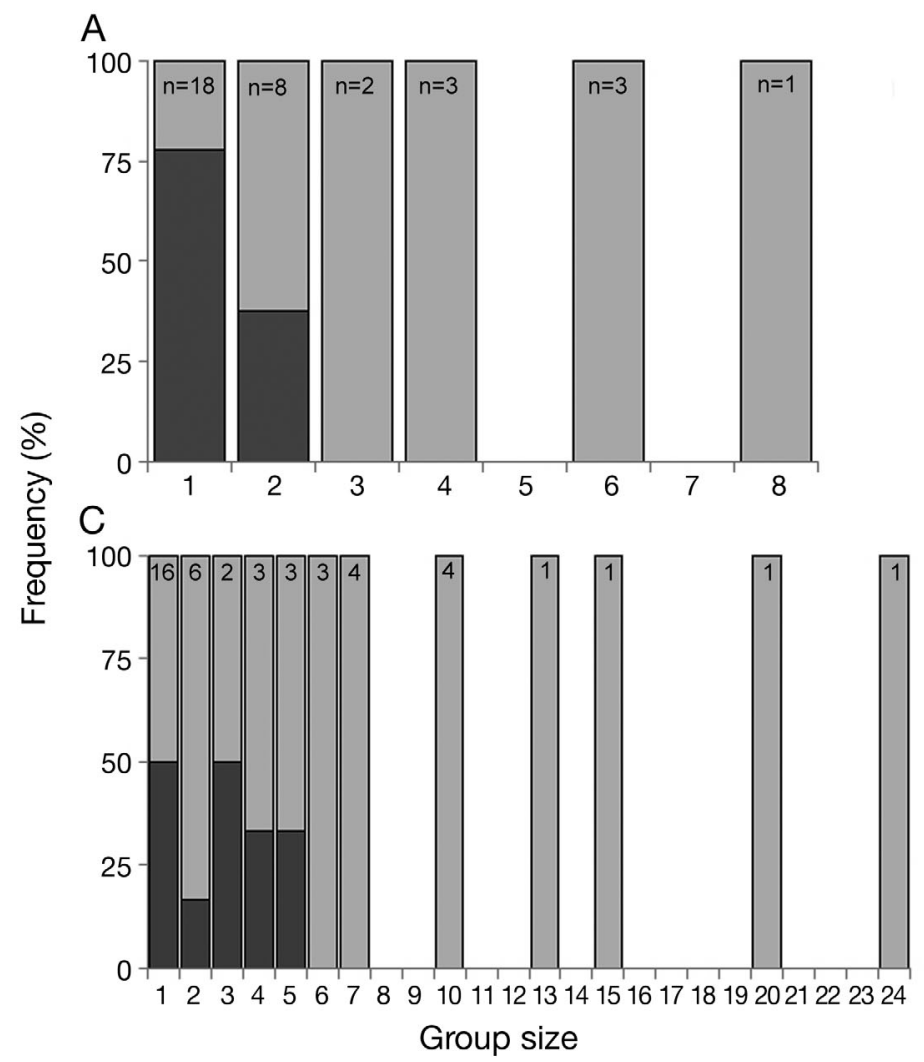

non-tandem main channel effort, and 4 individuals were recorded in side channels. Missed groups were significantly smaller than matched groups (MannWhitney $U$-test, $W=258.5, \mathrm{p}<0.0001$ ) (Fig. 4). Of the 35 sightings, $48.6 \%$ were missed by 1 team, including $77.8 \%$ of single animals, and $37.5 \%$ of groups of 2. All groups of 3 or more were sighted by both vessels (Fig. 5). There was no significant effect of river state on the proportion of sightings that were missed (Mann-Whitney $U$-test, $W=170.5, \mathrm{p}=0.76$ ). The best supported model was separated by more than 2 AICc points from all others and included a single capture probability influenced only by the covariate group size. The mean group size observed in the field, 1.98, was corrected for size bias to $1.50(\mathrm{CV}=8 \%)$ based on sighting probabilities generated by the model. The final abundance estimate for this subpopulation was $101(95 \% \mathrm{CI}=74-317, \mathrm{CV}=44.1 \%)$ (Table 2$)$.

\section{Taunsa to Ghazi Ghat}

Between Taunsa barrage and Ghazi Ghat, 14 groups were seen by the forward vessel and 15 by
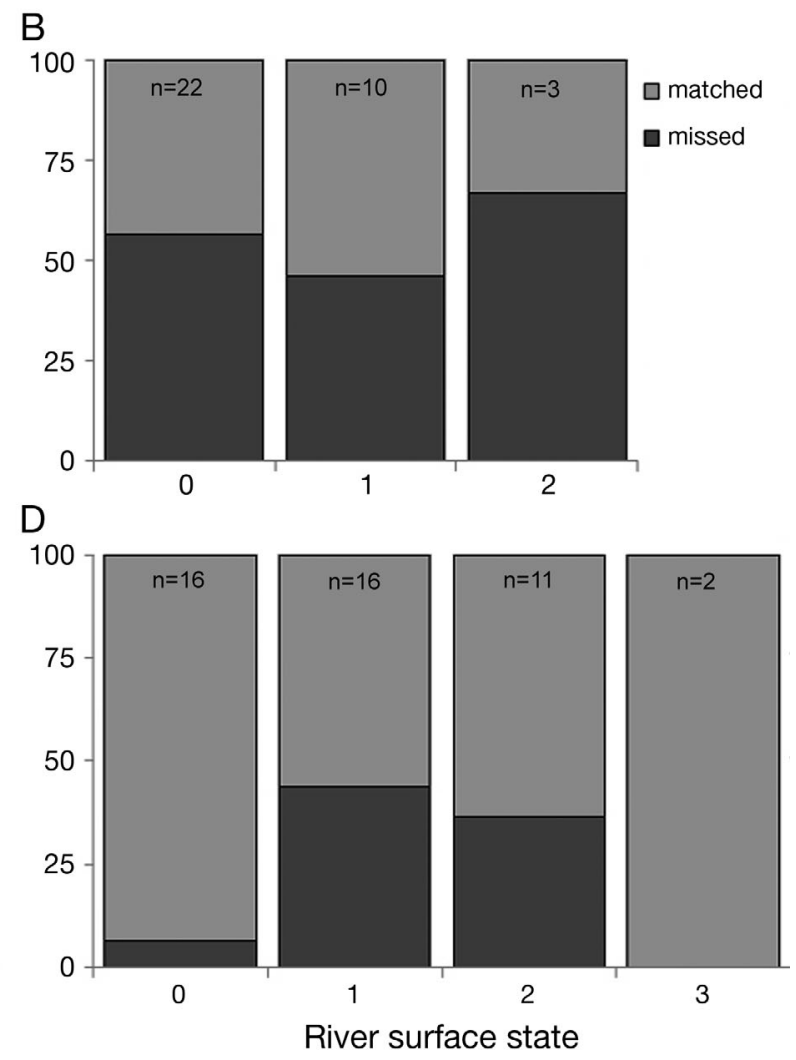

Fig. 4. Frequency of missed and matched sightings of Platanista gangetica minor (A) between Chashma and Taunsa barrages by group size and (B) by river surface state (see 'Materials and methods; Field surveys' for details), and (C) between Guddu and Sukkur barrages by group size and (D) by river surface state. Number of groups is given at the top of each column 


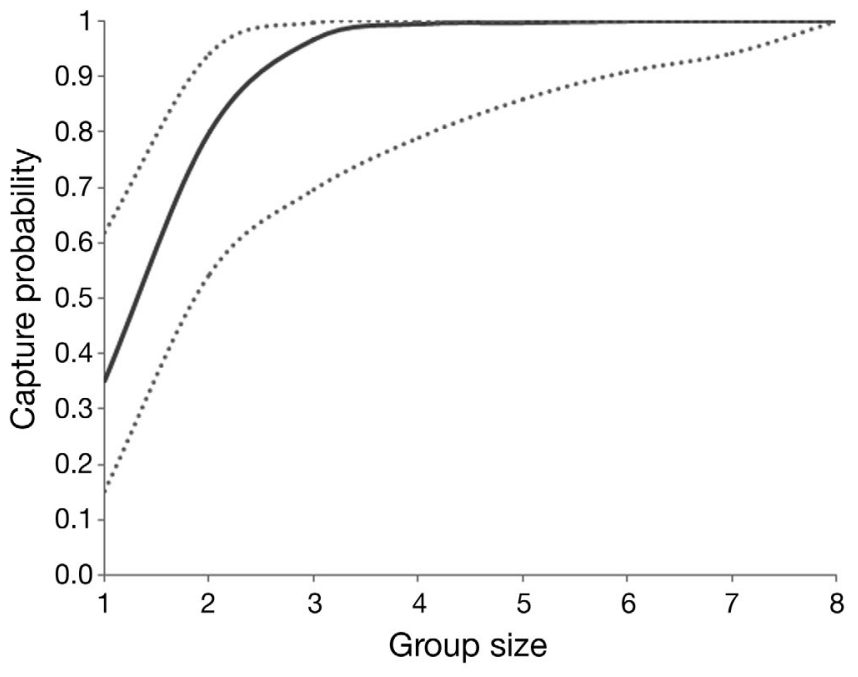

Fig. 5. Probability that Indus dolphin Platanista gangetica minor groups of different sizes were sighted by a survey vessel. Dotted lines represent $95 \%$ confidence intervals. Data from Chashma-Taunsa barrages only

the rear vessel. Thirteen were classified as matched, and only 3 were missed. There were 3 non-tandem sightings and no groups recorded in side-channels in this section. The top 3 candidate models that were averaged included the influence of river surface state on sighting probability. As the final models did not include the covariate group size, the mean group size recorded in the field $2.63(\mathrm{CV}=12.7 \%)$ was assumed to be unbiased. Abundance for this portion of the 3TG subpopulation was estimated to be $52(95 \% \mathrm{CI}=$ 50-102, CV $=14.9 \%$ ) (Table 2).

\section{Guddu to Sukkur}

In the MD subsection of the 4G-S subpopulation, 43 groups were seen by the forward vessel, 35 by the rear vessel, and 33 were classified as matched. Twenty seven groups were seen during non-tandem main-channel effort and 5 individuals in a side channel. All groups of 6 or more individuals were seen by both vessels, but $50 \%$ of single animals were missed. Matched groups were significantly larger than those that were missed (Mann-Whitney $U$-test, $W=88, \mathrm{p}<0.01$ ) and there was no obvious effect on sighting probability attributable to river state (Mann-Whitney $U$-test, $W=254, \mathrm{p}=0.13$ ) (Fig. 4). The model with the lowest AICc included the covariate group size and a different capture probability for each vessel. Corrected group size estimates were $4.73(\mathrm{CV}=11.0 \%)$ in the MD sub-

Table 2. Summary of Indus dolphin Platanista gangetica minor subpopulation abundance estimation. For river sections see Fig. 1. MD: moderate density subsection of the Guddu to Sukkur subpopulation; HD: high density subsection of the Guddu to Sukkur subpopulation. Strata refers to survey effort conducted with either tandem vessels or a single vessel, each of which were analysed differently (see 'Materials and methods'). CV: coefficient of variation; $n_{\mathrm{f}}, n_{\mathrm{r}}, n_{\mathrm{fr}}$ : number of sightings seen by the forward, rear and by both vessels, respectively, during tandem survey effort; $M_{\mathrm{t}+1}=$ number of unique individuals sighted during the survey; $\hat{p}$ : sighting probability; $f_{\mathrm{m}}$ : group correction for non-tandem effort; $\hat{g}$ : corrected number of tandem or non-tandem effort sightings; $n_{\mathrm{s}}$ : number of individuals recorded in side channels; $\bar{s}$ : corrected mean group size; $\hat{N}$ : abundance estimate; er: encounter rate; (-): not determined/not applicable

\begin{tabular}{|c|c|c|c|c|c|c|c|c|c|c|c|c|c|c|c|c|}
\hline $\begin{array}{l}\text { River section } \\
\text { Strata }\end{array}$ & $n_{\mathrm{f}}$ & $n_{\mathrm{r}}$ & $n_{\mathrm{fr}}$ & $M_{\mathrm{t}+1}$ & $\hat{p}$ & $f_{\mathrm{m}}$ & $f_{\mathrm{m}} \mathrm{CV}$ & $\hat{g}$ & $\hat{g} \mathrm{CV}$ & $n_{\mathrm{s}}$ & $\overline{\mathrm{s}}$ & $\overline{\mathrm{s}} \mathrm{CV}$ & $\hat{N}$ & $\hat{N C V}$ & $95 \% \mathrm{CI}$ & er \\
\hline \multicolumn{17}{|l|}{$2 \mathrm{C}-\mathrm{T}$} \\
\hline Tandem & 27 & 26 & 18 & - & 0.864 & - & - & 48.5 & 21.1 & - & 1.50 & 8.0 & 73 & 22.5 & - & - \\
\hline Non-tandem & 9 & - & - & - & - & 1.80 & 37.9 & 16.2 & - & 4 & 1.50 & 8.0 & 28 & 38.7 & - & - \\
\hline Total & - & - & - & 70 & - & - & - & - & - & - & - & - & 101 & 44.1 & $74-317$ & 0.34 \\
\hline \multicolumn{17}{|l|}{3 T-GG } \\
\hline Tandem & 14 & 15 & 13 & - & 0.999 & - & - & 16.4 & 5.0 & - & 2.63 & 12.7 & 43 & 13.7 & - & - \\
\hline Non-tandem & 3 & - & - & - & - & 1.17 & 5.80 & 3.5 & - & 0 & 2.63 & 12.7 & 9 & 14.0 & - & - \\
\hline Total & - & - & - & 50 & - & - & - & - & - & - & - & - & 52 & 14.9 & 50-102 & 0.80 \\
\hline \multicolumn{17}{|l|}{4 G-S MD } \\
\hline Tandem & 43 & 35 & 33 & - & 0.879 & - & - & 47.0 & 18.0 & - & 4.73 & 11.0 & 223 & 21.1 & - & - \\
\hline Non-tandem & 27 & - & - & - & - & 1.09 & 19.7 & 29.5 & - & 5 & 4.73 & 11.0 & 145 & 22.5 & - & - \\
\hline \multicolumn{17}{|l|}{4 G-S HD } \\
\hline Non-tandem & 91 & - & - & - & - & 1.09 & 19.7 & 99.5 & - & 0 & 9.26 & 9.1 & 922 & 21.7 & - & - \\
\hline Total & - & - & - & 1189 & - & - & - & - & - & - & - & - & 1289 & 33.4 & $1192-4120$ & 6.30 \\
\hline Grand total & - & - & - & 1309 & - & - & - & - & - & - & - & - & 1442 & 57.2 & $1312-7014$ & \\
\hline
\end{tabular}


section and $9.26(\mathrm{CV}=9.1 \%)$ in the HD subsection. The group correction factor of 1.09 was applied to the sightings in the HD sub-section to give a final abundance estimate of 1289 (95\% CI $=1192-4120$, $\mathrm{CV}=33.4 \%$ ) for this subpopulation (Table 2 ).

\section{Metapopulation abundance}

The sum of the above 3 abundance estimates and the animals sighted between Jinnah and Chashma, and Sukkur and Kotri, was 1447 (CV $=57.2 \%)$. A total of $300 \mathrm{~km}$ of dolphin habitat between Ghazi Ghat and Guddu barrage was not covered by the present survey, and therefore to provide an approximate estimate of subspecies abundance, we include data from previous surveys. In 2001, 200 dolphins were recorded in the $300 \mathrm{~km}$ section that was missed in 2006 (Braulik 2006). The direct counts recorded in the surveyed portion of this subpopulation in 2001 and 2006 (45 versus 44, respectively) were very similar, indicating that no large changes have occurred (Braulik 2006). However, conservatively allowing abundance in the unsurveyed area to have changed $\pm 50 \%$ in the intervening $5 \mathrm{yr}$ means that there may have been between 100 and 300 individuals in the unsurveyed stretch in 2006, and we therefore suggest that the subspecies numbered approximately 1550 to 1750 in 2006.

\section{Evaluation of potential bias}

A total of 1156 dive times were collected from 33 groups ranging in size from 1 to 5 individuals. Group dive time steadily decreased as group size increased because there is no synchronization in surfacing behaviour in this species (Table 3). Dolphin surfacings lasted from 0.60 to $1.76 \mathrm{~s}$, averaging $1.01 \mathrm{~s}(\mathrm{SD}=0.28 ; \mathrm{CV}=27.3 \% ; \mathrm{n}=103)$ and $61 \%$ of surfacings lasted for less than $1 \mathrm{~s}$. Although not specifically investigated, surface interval of individ-

Table 3. Sighting availability of Indus dolphin Platanista gangetica minor groups calculated from the mean sighting distance of $401 \mathrm{~m}$ which would be

traversed in $4.8 \mathrm{~min}$ at the target survey speed of $5 \mathrm{~km} \mathrm{~h}^{-1}$. n: no. of dives

\begin{tabular}{|lccc|}
\hline $\begin{array}{c}\text { Group } \\
\text { size }\end{array}$ & $\begin{array}{c}\text { Dive time (s) } \\
(\mathrm{n} ; 95 \% \mathrm{CI})\end{array}$ & $\begin{array}{c}\text { \% Time at } \\
\text { surface }\end{array}$ & $\begin{array}{c}\text { Surfacings within } \\
\text { sighting time window }\end{array}$ \\
\hline 1 & $78(181 ; 60-97)$ & 1.3 & 3.7 \\
2 & $56(282 ; 28-83)$ & 1.8 & 5.1 \\
3 & $51(337 ; 29-72)$ & 2.0 & 5.6 \\
$4 \& 5$ & $22(356 ; 6-37)$ & 4.7 & 12.8 \\
\hline
\end{tabular}

uals appeared to be unaffected by group size, and individuals seldom surfaced at the same time even in large groups. Consequently, the proportion of time spent at the surface increased with group size and ranged from 1.3 to $4.7 \%$ (Table 3 ). A frequency distribution of dolphin radial sighting distances (Fig. 2) indicated that detection probability was consistently high up to $400 \mathrm{~m}$ from the vessel and then slowly declined. It would take $4.81 \mathrm{~min}$, travelling at the survey speed of $5 \mathrm{~km} \mathrm{~h}^{-1}$ to cover $400 \mathrm{~m}$ and this was used as the time window within which animals could be detected. All of the divesurface cycles recorded were considerably shorter than $4.81 \mathrm{~min}$, and we conclude that the contribution of availability bias to total detection bias was negligible. Because there are more frequent surfacings in large groups, there are many more opportunities for them to be detected, which explains the lower detection probability of single animals; however, even single animals would be expected to surface several times in view of observers (Table 3).

For matched sightings, as group size increased so did the variability in the size estimates (GLM, p < 0.001 ). However, $30 \%$ of the group size estimates were identical, and $75 \%$ of estimates were within 2 individuals despite the time delay between surveys.

\section{DISCUSSION}

\section{Evaluation of survey methods}

Closed population capture-recapture analysis includes assumptions that, if violated, result in biased estimates of abundance. The assumption of population closure was met as each subpopulation is bounded into a linear strip by the lateral river banks and up- and downstream between irrigation barrages with closed gates. The 2 surveys were separated by less than $35 \mathrm{~min}$, so demographic changes would not have occurred. The assumption of equal capture probability for all groups in all circumstances was not met, but capture heterogeneity was accounted for in the model. Groups moving, and therefore not being recognized as matched (analogous to capture loss), may have occurred on occasion, but the high proportion of matched sightings $(75.3 \%)$ and the fact that matched sightings were on average only $200 \mathrm{~m}$ from one another indicate that this was not a significant source of bias. 
To reduce the potential for capture loss, group movement direction was included in the matching process, and the time lag between survey vessels was kept as short as possible. However, a separation of at least 1 $\mathrm{km}$ was essential so that the forward vessel did not interfere with, or influence, the ability of the rear observers to locate dolphins.

The greatest uncertainty involved in this study is the ability to correctly recognise captures. Individuals within Indus dolphin groups are often quite dispersed, and therefore the group locations used in the matching process are inherently inexact. In addition, the exact position was recorded when a group was judged to be perpendicular to the vessel, so does not necessarily represent the center of the group, which may have contributed to errors in recognising matched sightings. However, the frequency distribution of distances between potentially matched sightings demonstrates that there is little ambiguity in identifying matches, the sensitivity analysis showed little change in the number of matches even when quite different distance thresholds were used, and the great majority of sightings could be readily determined as matched or missed. A final capture-recapture assumption is that capture does not affect the probability of recapture, and the potential for this was also accounted for in the models. The best-fitting models for the 4G-S MD subsection included a lower capture probability for the rear survey vessel, which might suggest that dolphins avoided the vessels in the high density area. In all other areas, dolphins had a uniform capture probability which indicates no vessel attraction or avoidance behaviour. An additional source of potential downward bias in this survey is that animals were missed because they were too distant from the observers. To minimise this bias, geographic coverage of available habitat was maximised by surveying the entire length of the Indus main channel and deploying a separate boat to survey large side channels, behind islands and the far side of wide channel habitat. Detection probability was maximised by surveying only in excellent and good survey conditions and at a relatively slow speed. Perpendicular sighting distance could not be generated; however, mean sighting distance was consistently greater than half the mean river width, so the assumption that the majority of dolphins within the river channel could be detected is not unreasonable. In especially wide sections of the river it is still probable that dolphins were missed. This can be addressed in future surveys if channel width at sighting locations is collected and included as a covariate in models.
Availability and perception bias

Indus dolphin groups of all sizes surfaced frequently and were available to be detected by observers; the failure of observers to detect or recognise surfacings (perception bias) was therefore primarily responsible for missed groups. Dawson et al. (2008) suggested that perception bias tends to be largest for species (such as Platanista gangetica) that occur as single animals or in small groups and do not show much of the body when surfacing. Perception bias is often highest for inexperienced observers (Barlow 1988), and it is likely that observer inexperience contributed to the higher proportion of missed groups in the $2 \mathrm{C}$ - $\mathrm{T}$ subpopulation, which was the first to be surveyed. This reinforces the importance of training and observer experience in future surveys.

\section{Bias in group size estimation}

Estimation of group size for this species is challenging because groups are dispersed and individuals do not surface in synchrony. Increased variability and bias of group size estimates with increasing group size has been documented in many other surveys (Carretta et al. 1998, Gerrodette et al. 2002, Rugh et al. 2008). One hypothesis to explain the decrease in precision of Indus dolphin group size estimates as group size increases is that the unsynchronised surfacing behaviour and lack of group cohesion means a longer observation time is required to estimate the size of large groups; during a downstream survey, however, sufficient time is not always available. Biased group size estimates are potentially a smaller problem for Indus dolphins than for marine dolphins that form schools of several hundreds and where sighting conditions are often poor (Barlow 1988); however, future surveys of this species will need to consider methods to improve or calibrate group size estimates, especially in high density areas.

\section{Abundance and encounter rate}

At least 10 Indus dolphin subpopulations have been extirpated in the last century (Reeves et al. 1991). The farthest upstream (1J-C) and downstream (5S-K) Indus subpopulations and the one in the Beas River are each estimated at 10 or fewer individuals and are unlikely to persist in the long-term, leaving only 3 that are potentially viable. Conserving the $2 \mathrm{C}$ - $\mathrm{T}$ subpopulation is of high priority, because it is the smallest of 
these 3 and its loss would mean Indus dolphins remain in only approximately $550 \mathrm{~km}$ of river, dramatically increasing the vulnerability of the subspecies.

Encounter rate in the $4 \mathrm{G}-\mathrm{S}$ subpopulation was 6.30 dolphins linear $\mathrm{km}^{-1}$, peaking at 10.35 dolphins linear $\mathrm{km}^{-1}$ in an $80 \mathrm{~km}$ section. These are the highest encounter rates reported for any river cetacean. High densities of Amazon River dolphins have been recorded in specific favourable habitats (4.2 linear $\mathrm{km}^{-1}$ ) (Martin \& da Silva 2004), but the encounter rates reported here are more than double those in the Amazon and occur over a much wider area. Other freshwater cetaceans normally occur at less than 2.00 dolphins linear $\mathrm{km}^{-1}$ (Smith et al. 2001, Kreb 2005, Choudhary et al. 2006, Beasley 2007, Smith et al. 2007, Zhao et al. 2008, Wakid 2009). Given the degree of disturbance to the natural flow and sediment transport regime of the Indus River system and the fact that this subpopulation receives pollution from upstream, it is hard to understand how the local environment can support such unusually high densities of dolphins. However, the present survey was conducted when animals were concentrated by dryseason flow levels. The high observed density is presumably ephemeral because for much of the year river discharge is higher, and density and competition for resources is reduced. At present, little quantitative data is available as a basis for comparing habitat quality, prey availability, and dolphin mortality rates in the $4 \mathrm{G}-\mathrm{S}$ subpopulation with other parts of the Indus River to show why this area is so important for Indus dolphins.

\section{Trends in abundance of the Guddu to Sukkur subpopulation}

The direct counts generated by the present survey and those from 2001 (Braulik, 2006) used identical field methods and recorded very similar counts in every subpopulation except for between Guddu and Sukkur (Table 4) where the 2006 count was 64.5\% greater than 2001. Direct count surveys were also conducted by Sindh Wildlife Department (SWD) during the same time period. They reported 500 dolphins between Guddu and Sukkur barrages in 2001, and 807 in 2006 (SWD unpubl. data); an increase of $61.4 \%$ over the same 5 yr period. The absolute counts recorded by the 2 groups were different due to different methods, but both recorded a similar increase.

Since 1974, at least 22 direct counts of the GudduSukkur dolphin subpopulation have been conducted by SWD (Reeves \& Chaudhry 1998, Bhaagat 1999,
Table 4. Comparison of direct counts of Indus dolphin Platanista gangetica minor subpopulations recorded in 2001 and 2006 using identical survey methods

\begin{tabular}{|lcc|}
\hline Subpopulation & $\begin{array}{c}2001 \\
\text { (Braulik 2006) }\end{array}$ & $\begin{array}{c}2006 \\
\text { (present study) }\end{array}$ \\
\hline 1J-C & 2 & 1 \\
2C-T & 84 & 82 \\
3T-GG & 45 & 44 \\
$4 \mathrm{G}-\mathrm{S}$ & $775^{\mathrm{a}}$ & 1275 \\
$5 \mathrm{~S}-\mathrm{K}$ & 18 & $4^{\mathrm{b}}$ \\
an 2001, 602 dolphins were counted, and after extrapola- \\
tion of a conservative mean encounter rate (3.6 km ${ }^{-1}$ ) to \\
an unsurveyed 33.3 km segment, 725 were estimated \\
(Braulik 2006). As the unsurveyed segment was in a \\
very high density area, application of the encounter rate \\
from adjacent channels (5.0 km ${ }^{-1}$ ) is more realistic and \\
we therefore applied this to generate a revised estimate \\
of 775 animals in 2001 in this subpopulation \\
b The whole 5S-K subpopulation was not surveyed in \\
2006, so figures cannot be directly compared between \\
years
\end{tabular}

Braulik 2006). Survey methods have not been comprehensively documented, and the reported dolphin counts do not include measures of precision and presumably also underestimate the actual population size, as no corrections were made for animals that were missed. However, they included standard elements, with visual observers on oar-powered vessels travelling downstream during the dry season, and there was some consistency in observers over years. If the methods, and hence the proportion of dolphins missed, remained relatively stable over time, the surveys can provide an indication of trends in abundance in that subpopulation. The counts increase from 138 in 1974 (Pilleri \& Zbinden 1973-74) to 902 in 2008 (SWD unpubl. data) (Fig. 6) and show an exponential, statistically significant, rate of increase (linear regression: $F=135, \mathrm{p}<0.001$ ) equivalent to approximately $5.65 \%$ per yr. The lack of confidence intervals on all of these counts means that firm conclusions about population growth rates cannot be made; however, all surveys indicate that there has been some increase in the Guddu to Sukkur subpopulation since the 1970s. A power analysis showed that count CVs as large as $54 \%$ would have allowed the observed trend to be detected at a $5 \%$ confidence level (Gerrodette 1987, Gerrodette \& Brandon 2000).

Until the 1970s, dolphins were hunted in Sindh (Pilleri \& Zbinden 1973-74). Hunting was banned by the Sindh Wildlife Act (1972) and, in 1974, the Indus Dolphin Reserve was established between Guddu and Sukkur barrages. The probable increase in dol- 


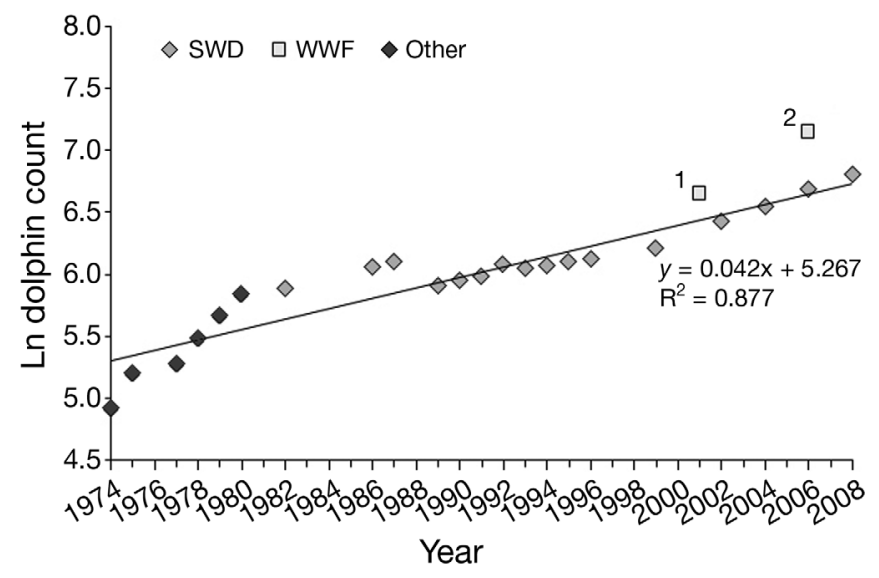

Fig. 6. Natural logarithm of Indus River dolphin Platanista gangetica minor direct counts recorded between Guddu and Sukkur barrages between 1974 and 2008. The natural logarithm was applied to the counts to transform the exponential increase into a linear increase that could be examined using linear regression. SWD: Counts conducted by Sindh Wildlife Department; WWF: World Wildlife Fund (WWF)-Pakistan and Ministry of Environment's Pakistan Wetlands Programme; Other: counts conducted by authors other than SWD or WWF, for details see Braulik (2006) and Bhaagat (1999). The WWF point labelled 1 represents data from Braulik (2006), and the WWF point labeled 2 represents the direct count recorded in the present study

phin abundance between Guddu and Sukkur likely signifies population recovery following the cessation of dolphin hunting. It is unlikely that the increase is due to improvements in habitat or prey availability, as new dams and barrages continue to be constructed, the Indus flood cycle and sediment transport processes have been greatly disrupted, dry season discharge has declined, and levels of pollution have increased dramatically as Pakistan becomes industrialized (World Bank 2005). The river corridor in upper Sindh is a tribal area subject to banditry and lawlessness, resulting in low levels of human activity compared to other parts of the river that may contribute to low dolphin mortality rates. Another factor that could contribute to the increase is the role of immigration from other subpopulations. It is possible that dolphins traverse irrigation barrages and move between subpopulations during the few weeks of the year that gates are fully open (Reeves et al. 1991, Braulik 2006). Many factors are likely to influence whether animals move through a particular barrage, including its design, river discharge, hydrology, adjacent dolphin density, and most importantly, how the barrage is operated and how frequently the gates are opened. It is likely that dolphins never traverse some barrages but frequently traverse others. However, during January 2009, in the only few weeks of the year when the gates of Sukkur barrage are open, a radio-tagged dolphin moved through the barrage 3 times, finally becoming trapped downstream (WWFPakistan unpubl. data). If the predominant movement of migrants is downstream, this 'downstream migratory attrition' would result in the decline of all upstream subpopulations and the increase of those downstream (Reeves 1991, Reeves et al. 1991). As the increase in counts from 2001 to 2006 between Guddu and Sukkur exceeded the total number of animals recorded in all other subpopulations, immigration cannot be solely responsible. The large proportion of calves and juveniles observed $(11 \%)$ suggests that this subpopulation is reproducing rapidly and if immigration does occur, it is likely supplementing the increase, rather than being solely responsible for it. It is essential that there is continued monitoring of the Indus subpopulations, using standard survey methods to provide more robust data for determining trends in abundance, and radio or satellite tracking of dolphins in different locations and seasons will help to shed light on dolphin movement between subpopulations.

\section{Conclusions}

In medium and low density areas the survey method was effective, but at very high densities, greater than 6 dolphins linear $\mathrm{km}^{-1}$, it was not possible to apply. Such densities, however, are exceptional and do not occur elsewhere in Asia. Whether using tandem vessels or independent observers on a single vessel, the direct count capture-recapture survey method following a thalweg transect shows good potential for abundance estimation of dolphins in confined areas or shallow rivers, such as the Indus, Ganges, Brahmaputra, and Ayeyarwady, where dolphin densities are generally low and traditional methods for estimating abundance cannot be easily applied. One distinct advantage of the method is that despite the more complex analysis, the existing relatively low-cost field survey methods do not need to be greatly modified. However, in each new survey it is essential that there be a careful evaluation of the reliability of matches.

The future of the South Asian river dolphins is intimately tied to the region's water security. South Asia has approximately $25 \%$ of the world's human population but only $4.5 \%$ of its renewable water resources (Babel \& Wahid 2008). The vast majority of water needs are met by the region's rivers, per capita water availability is plummeting, and in Pakistan demands 
for fresh water are predicted to outstrip availability before 2025 (Siddiqi \& Tahir-Kheli 2004). The temporary increase in river discharges predicted due to climate change will be overwhelmed by increased water demand (Palmer et al. 2008). There are numerous plans to increase river withdrawals, to transfer water between rivers or river basins, and increase water storage capability by constructing high dams (Ghosh et al. 2003, Bosshard \& Lawrence 2006, de Fraiture \& Wichelns 2010, Dutta 2010), which will further deplete river flows and disrupt the natural flow regime. Losses of freshwater biodiversity are inevitable and the prospects for the South Asian river dolphins uncertain.

Acknowledgements. The Pakistan Provincial Wildlife Departments, Police Forces, Irrigation Departments, Ministry of Environment, and Water and Power Development Authority (WAPDA) facilitated the expedition. Logistical support was undertaken by R. Ahmed, M. Azam, M. Abduhu and A. Rana of the Adventure Foundation Pakistan. Members of the scientific teams included: K. Javed, M. Ahmad, M. Chaudhry, S. Khan, S. Hussain, S. Ahmad, M. Hamid, I. Khaskheli, A. Bullo and Z. Ali. Invaluable support was provided by A. Habib, M. Malik, I. Tajwer, A. Khan, G. Akbar and M. Arshad. The manuscript was improved by input from P. Hammond, R. Williams and R. Reeves. Valuable statistical input was provided by S. Hedley. Funding came from WDCS, WWF-Pakistan, and the Pakistan Wetlands Programme which is funded by UNDP-GEF and the Netherlands Embassy.

\section{LITERATURE CITED}

Babel MS, Wahid SW (2008) Freshwater under threat: South Asia. United Nations Environment Programme, Nairobi

Barlow J (1988) Harbor porpoise, Phocoena phocoena, abundance estimation for California, Oregon, and Washington: I. Ship surveys. Fish Bull 86:417-432

Barlow J, Oliver CW, Jackson TD, Taylor BL (1988) Harbor porpoise, Phocoena phocoena, abundance estimation for California, Oregon, and Washington: II. Aerial surveys. Fish Bull 86:433-444

Beasley I (2007) Conservation of the Irrawaddy dolphin, Orcaella brevirostris (Owen in Gray, 1866) in the Mekong River: biological and social considerations influencing management. PhD thesis, James Cook University, Townsville

Behera SK, Nawab A, Rajkumar B (2008) Preliminary investigations confirming the occurrence of Indus River dolphin Platanista gangetica minor in River Beas, Punjab, India. J Bombay Nat Hist Soc 105:90-126

Bhaagat HB (1999) Introduction, distribution, conservation and behavioral ecology of Indus blind dolphin (Platanista indi) in River Indus (dolphin reserve), Sindh-Pakistan. Tiger Paper 26:11-16

Borchers DL, Buckland ST, Zucchini W (2002) Estimating animal abundance: closed populations. Springer-Verlag, London

Bosshard P, Lawrence S (2006) Pakistan's rot has World Bank roots. Far Eastern Economic Review May 2006:39-43

Braulik GT (2006) Status assessment of the Indus River dolphin, Platanista gangetica minor, March-April 2001. Biol Conserv 129:579-590

Braulik GT, Smith BD, Chaudhry AA (2004) Platanista gangetica ssp. minor. In: IUCN 2010 IUCN Red List of Threatened Species, Ver 20102. www.iucnredlist.org/ apps/redlist/details/41757/0 (accessed 04 August 2010)

Buckland ST, Anderson DR, Burnham KP, Laake JL, Borchers DL, Thomas L (2001) Introduction to distance sampling: estimating abundance of biological populations. Oxford University Press, Oxford

Burnham KP, Anderson DR (2002) Model selection and multi- model inference: a practical information-theoretic approach, 2nd edn. Springer-Verlag, New York, NY

Carretta JV, Forney KA, Laake JL (1998) Abundance of southern California coastal bottlenose dolphins estimated from tandem aerial surveys. Mar Mamm Sci 14: 655-675

Choudhary SK, Smith BD, Dey S, Dey S, Prakash S (2006) Conservation and biomonitoring in the Vikramshila Gangetic dolphin sanctuary, Bihar, India. Oryx 40: 189-197

Crete M, Vandal D, Rivest LP, Potvin F (1991) Double counts in aerial surveys to estimate polar bear numbers during the ice-free period. Arctic 44:275-278

$>$ Dawson S, Wade P, Slooten E, Barlow J (2008) Design and field methods for sighting surveys of cetaceans in coastal and riverine habitats. Mammal Rev 38:19-49

> de Fraiture C, Wichelns D (2010) Satisfying future water demands for agriculture. Agric Water Manag 97:502-511

$>$ Dudgeon D, Arthington AH, Gessner MO, Kawabata Z-I and others (2006) Freshwater biodiversity: importance, threats, status and conservation challenges. Biol Rev 81: 163-182

Dutta AP (2010) Reservoir of dams. Down to earth. May 1-15: 32-39 www.downtoearth.org/in/content/reservoir-dams

$>$ Gerrodette T (1987) A power analysis for detecting trends. Ecology 68:1364-1372

Gerrodette T, Brandon J (2000) Trends. Ver. 3.0 Windows. Southwest Fisheries Science Center, La Jolla, CA

Gerrodette T, Perryman WL, Barlow J (2002) Calibrating group size estimates of dolphins in the eastern tropical pacific ocean. Southwest Fisheries Science Center, National Marine Fisheries Service, NOAA, La Jolla, CA

Gerrodette T, Taylor BL, Swift R, Rankin S, Jaramillo-Legorreta AM, Rojas-Bracho L (2011) A combined visual and acoustic estimate of 2008 abundance, and change in abundance since 1997, for the vaquita, Phocoena sinus. Mar Mamm Sci 27:E79-100

Ghosh A, Sikdar PK, Ashoke KD (eds) (2003) Interlinking of Indian Rivers. ACB Publications, Kolkata

> Graham A, Bell R (1989) Investigating observer bias in aerial survey by simultaneous double-counts. J Wildl Manag 53:1009-1016

Hammond PS (2009) Mark-recapture. In: Perrin WF, Würsig B, Thewissen JGM (eds) Encyclopedia of marine mammals, 2nd edn. Academic Press, San Diego, CA, p 705-709

Hammond PS, Berggren P, Benke H, Borchers DL and others (2002) Abundance of harbour porpoise and other cetaceans in the North Sea and adjacent waters. J Appl Ecol 39:361-376

Hiby L, Krishna MB (2001) Line transect sampling from a curving path. Biometrics 57:727-731 
Hiby AR, Lovell P (1998) Using aircraft in tandem formation to estimate abundance of harbour porpoise. Biometrics 54:1280-1289

Horvitz DG, Thompson DJ (1952) A generalization of sampling without replacement from a finite universe. J Am Stat Assoc 47:663-685

Huggins RM (1989) On the statistical-analysis of capture experiments. Biometrika 76:133-140

IUCN (International Union for Conservation of Nature) (2010) IUCN Red List of Threatened Species, ver. 2010.2. www.iucnredlist.org (accessed 3 August 2010)

IWC (International Whaling Commission) (2001) Annex K report of the standing sub-committee on small cetaceans. J Cetacean Res Manag 3:S263-290

Kreb D (2005) Abundance of freshwater Irrawaddy dolphins in the Mahakam River in East Kalimantan, Indonesia, based on mark-recapture analysis of photo-identified individuals. J Cetacean Res Manag 6:269-277

Marsh H, Sinclair DF (1989) Correcting for visibility bias in strip transect aerial surveys of aquatic fauna. J Wildl Manag 53:1017-1024

Martin AR, da Silva VMF (2004) River dolphins and flooded forest: seasonal habitat use and sexual segregation of botos Inia geoffrensis in an extreme cetacean environment. J Zool 263:295-305

Palmer MA, Liermann CAR, Nilsson C, Florke M, Alcamo J, Lake PS, Bond N (2008) Climate change and the world's river basins: anticipating management options. Front Ecol Environ 6:81-89

Pilleri G, Zbinden K (1973-74) Size and ecology of the dolphin population (Platanista indi) between Sukkur and Guddu Barrages, Indus River. Investigations on Cetacea 5:59-70

Reeves RR (1991) Conservation of the bhulan (blind river dolphin) in the Punjab. Natura, WWF-Pakistan, Lahore p 3-22

Reeves RR, Chaudhry AA (1998) Status of the Indus River dolphin Platanista minor. Oryx 32:35-44

Reeves RR, Chaudhry AA, Khalid U (1991) Competing for water on the Indus Plain: Is there a future for Pakistan's river dolphins? Environ Conserv 18:341-349

Rugh DJ, Muto MM, Hobbs RC, Lerczack JA (2008) An assessment of shore-based counts of gray whales. Mar Mamm Sci 24:864-880

Samuel MD, Pollock KH (1981) Correction of visibility bias in aerial surveys where animals occur in groups. J Wildl Manag 45:993-997

Siddiqi TA, Tahir-Kheli S (eds) (2004) Water needs in South Asia: closing the demand-supply gap. Global Environment and Energy in the 21st century, Honolulu, HI

Editorial responsibility: Brendan Godley, University of Exeter, Cornwall Campus, UK
Smith BD, Reeves RR (2000) Survey methods for population assessment of Asian river dolphins. In: Reeves RR, Smith BD, Kasuya T (eds) Biology and conservation of freshwater cetaceans in Asia. IUCN, Gland, p 97-115

Smith BD, Ahmed B, Ali ME, Braulik GT (2001) Status of the Ganges river dolphin or shushuk Platanista gangetica in Kaptai Lake and the southern rivers of Bangladesh. Oryx 35:61-72

Smith BD, Braulik G, Sinha RK (2004) Platanista gangetica ssp. gangetica IUCN 2010 IUCN Red List of Threatened Species, ver. 20102 www.iucnredlist.org/apps/redlist/ details/41756/0 (accessed 4 August 2010)

Smith BD, Braulik G, Strindberg S, Ahmed B, Mansur R (2006) Abundance of Irrawaddy dolphins (Orcaella brevirostris) and Ganges River dolphin (Platanista gangetica gangetica) estimated using concurrent counts made by independent teams in waterways of the Sundarbans mangrove forest in Bangladesh. Mar Mamm Sci 22: $527-547$

Smith BD, Shore RG, Lopez A (eds) (2007) Status and conservation of freshwater populations of Irrawaddy dolphins. Wildlife Conservation Society Working Paper No. 31

Stanley TR, Burnham KP (1998) Information-theoretic model selection and model averaging for closed-population capture-recapture studies. Biom J 40:475-494

Strayer DL, Dudgeon D (2010) Freshwater biodiversity conservation: recent progress and future challenges. J N Am Benthol Soc 29:344-358

Turvey ST, Pitman RL, Taylor BL, Barlow J and others (2007) First human-caused extinction of a cetacean species? Biol Lett 3:537-540

- Vidal O, Barlow J, Hurtado LA, Torre J, Cendón P, Ojeda Z (1997) Distribution and abundance of the Amazon River dolphin (Inia geoffrensis) and the tucuxi (Sotalia fluviatilis) in the upper Amazon River. Mar Mamm Sci 13: $427-445$

Wakid A (2009) Status and distribution of the endangered Gangetic dolphin (Platanista gangetica gangetica) in the Brahmaputra River within India in 2005. Curr Sci 97 : 1143-1151

Williams BK, Nichols JD, Conroy MJ (2002) Analysis and management of animal populations. Academic Press, London

World Bank (2005) Pakistan country water resources assistance strategy. Agriculture and Rural Development Unit, South Asia Region, World Bank

Zhao X, Barlow J, Taylor BL, Pitman RL and others (2008) Abundance and conservation status of the Yangtze finless porpoise in the Yangtze River, China. Biol Conserv 141:3006-3018

Submitted: August 25, 2010; Accepted: February 11, 2012 Proofs received from author(s): May 22, 2012 